\title{
Large eddy simulation of a reacting spray flame with multiple realizations under compression ignition engine conditions
}

Yuanjiang Pei ${ }^{\mathrm{a}, *}$, Sibendu Som ${ }^{\mathrm{a}}$, Eric Pomraning ${ }^{\mathrm{b}}$, Peter K. Senecal ${ }^{\mathrm{b}}$, Scott

A. Skeen ${ }^{\mathrm{c}}$, Julien Manin ${ }^{\mathrm{c}}$, Lyle M. Pickett ${ }^{\mathrm{c}}$

${ }^{a}$ Transportation Technology Research and Development Center

Argonne National Laboratory, Argonne, IL 60439, USA

${ }^{b}$ Convergent Science Inc., Madison, WI, 53719, USA

${ }^{c}$ Combustion Research Facility

Sandia National Laboratory, Livermore, CA 94550, USA

\section{Abstract}

An n-dodecane spray flame (Spray A from Engine Combustion Network) was simulated using a $\delta$ function combustion model along with a dynamic structure large eddy simulation (LES) model to evaluate its performance at engine-relevant conditions and to understand the transient behavior of this turbulent flame. The liquid spray was treated with a traditional Lagrangian method and the gas-phase reaction was modeled using a $\delta$ function combustion model. A 103-species skeletal mechanism was used for the n-dodecane chemical kinetic model. Significantly different flame structures and ignition processes are observed for the LES compared to those of Reynolds-averaged Navier-Stokes (RANS) predictions. The LES data suggests that the first ignition initiates in a lean mixture and propagates to a rich mixture, and the main ignition happens in the rich mixture, preferably less than 0.14 in mix-

\footnotetext{
*Corresponding author, Phone number: +1 (630) 252-5237

Email address: ypei@anl.gov (Yuanjiang Pei)
} 
ture fraction space. LES was observed to have multiple ignition spots in the mixing layer simultaneously while the main ignition initiates in a clearly asymmetric fashion. The temporal flame development also indicates the flame stabilization mechanism is auto-ignition controlled and modulated by flame propagation. Soot predictions by LES present much better agreement with experiments compared to RANS, both qualitatively and quantitatively. Multiple realizations for LES were performed to understand the realization to realization variation and to establish best practices for ensemble-averaging diesel spray flames. The relevance index analysis suggests that an average of 5 and 6 realizations can reach $99 \%$ of similarity to the target average of 16 realizations on the mixture fraction and temperature fields, respectively. However, more realizations are necessary for the hydroxide $(\mathrm{OH})$ and soot mass fractions due to their high fluctuations.

Keywords:

Spray A, Large eddy simulation, Engine Combustion Network, Diesel, Ignition, n-Dodecane 


\section{Introduction}

Vehicles equipped with internal combustion engines (ICEs) will still be the main transportation tools in the foreseeable future. Due to their tremendous volume and high frequency of use, there are still immense benefits to obtain by continuously striving to increase the fuel efficiency and reduce emissions for these engines. In doing that, it is of paramount importance and, also extremely challenging, to understand the in-cylinder combustion process, e.g., cycle-to-cycle variations associated with the stochastic processes and varied ignition and emission characteristics due to local inhomogeneity [1]. In the last two decades, significant progress has been made in using experimental techniques to understand the in-cylinder process to assist engine design and optimization processes $[2,3]$. Despite these significant advancements, the state-of-the-art experiments can only provide partial information about the in-cylinder process due to the limitations of the measurement techniques. On the other hand, computational fluid dynamics (CFD) has been a critical complement in that context and can provide a complete, at least qualitative, picture of the in-cylinder process.

The Reynolds-averaged Navier-Stokes (RANS) turbulence model has been used extensively for diesel engine simulations due to its computational efficiency and it is expected to remain the mainstay turbulence model in the industry for the foreseeable future. Alternatively, large eddy simulations (LES) can potentially deal with complex flows by resolving a large disparity of length scales, which makes this turbulence model, although significantly more expensive, more attractive in the engine community. A detailed description of LES theory and modelling can be found in the literature by Pope $[4,5]$ 
and a recent review of different LES turbulence models for engines can be found in the literature by Rutland [6].

Recently, some LES studies have been performed in conjunction with different combustion models to examine its performance on diesel spray flame at engine-like conditions. Bekdemir et al. [7] implemented a flamelet generated manifold (FGM) model in the context of a Smagorinshky LES model and simulated a diesel spray flame. The mesh used had the minimum cell size of $0.08 \mathrm{~mm}$ near the nozzle exit and gradually increased to $0.8 \mathrm{~mm}$ in the downstream region, yielding about 4.3 million cells in total. The flame characteristics were well captured and it was demonstrated that the tabulation flamelet method could be used for LES engine simulations also. Tillou et al. [8] simulated a diesel jet using a Smagorinsky LES model coupled with a flamelet combustion model with tabulated chemistry and assessed the variability of spray combustion for 15 realizations. The mesh details were similar to the one in Ref. [7], but with 1.8 million total cells. It was concluded that the variability in terms of auto-ignition delay was negligible, with about a $10 \%$ variation on the heat release rate in the later stage of combustion. Ameen and Abraham [9] used a Smagorinsky LES model coupled with an unsteady flamelet progress variable (UFPV) model to simulate an n-heptane gas jet on a mesh with 7.9 million cells. The computational cells stretched from 0.05 to $0.1 \mathrm{~mm}$ axially (from nozzle exit to downstream region) and from 0.02 to $0.34 \mathrm{~mm}$ radially (from spray axis to the off-axis region). They analyzed the flame stabilization mechanism and compared the results to a RANS-based model. It was found that the ensemble-averaged quasi-steady lift-off length predicted by both LES and RANS were similar 
and the fundamental physics affecting the lift-off length were the same although the transient behavior was vastly different. Another LES study of a diesel reacting spray was conducted by Irannejad et al. [10], who used a LES-filtered mass density function (FMDF) method to assess the effect of turbulence-chemistry-interaction (TCI). The LES grid size was $0.2 \mathrm{~mm}$ in spray-axis direction and stretched on in other directions. There were 120 million Monte Carlo particles to statistically represent the flow field in the simulations. It was found that the main ignition first occurred in the fuel-rich regions and the flame lift-off was strongly dependent on the spray parameters, gas temperatures, and oxygen concentrations, etc. The most recent study is from Gong et al. [11] who investigated the auto-ignition and stabilization mechanisms of an n-dodecane spray flame at engine conditions using LES and detailed chemical kinetics models. A uniform mesh with cell size of 0.25 $\mathrm{mm}$ was adopted. It was found that two-stage ignition behavior was predicted, and auto-ignition and flame propagation were competing to explain the flame lift-off stabilization among the two ambient temperatures of 900 and $1000 \mathrm{~K}$ considered.

Progress has been made through those LES studies of reacting diesel flames. However, a systematic study of mesh resolutions, flame transient processes, multiple realizations, different ambient conditions, and soot predictions has been lacking. In this study, a $\delta$ function combustion model is used in conjunction with a dynamic structure LES model to simulate the Spray A condition associated with the Engine Combustion Network (ECN) [12]. The most significant difference of this study compared to the previous studies is that a systematic investigation is conducted on a high-fidelity reso- 
lution mesh with a cell size of $0.0625 \mathrm{~mm}$ in the entire spray and combustion regions. To the best of our knowledge, such fine mesh resolution is perhaps the most resolved LES study of the ECN spray flames and, in general, for the spray flames under compression ignition engine conditions. The high-fidelity data obtained are examined in detail in this paper and compared to those from a RANS-based model, and available experimental data. A similar LES study at coarser resolutions has also been performed in the past by Som et al. [13] and this study further extends the findings of Som et al.

The paper is organized as follows. The first part briefly describes the experimental data used to verify the modeling results, followed by a description of the model setup. The next section presents the studies of mesh resolution, detailed transient flame behaviors, "quasi-steady" state flame, different ambient temperature effect, soot predictions, and realization variations. The conclusion and summary are reported in the last section.

\section{Experimental data}

The spray experiments presented in this work were performed in a constant volume pre-burn chamber, which has provided a platform for model development and validation at engine relevant conditions [14-27]. A detailed description of the experimental setup and measurement procedures can be found in the literature [28-30]. Briefly, the combustion vessel is nearly cubical with an interal volume of approximately 1 liter. Sapphire windows provide optical access to the spray event from four sides. Prior to and during operation, the temperature of the entire vessel is maintained at $461 \mathrm{~K}$ by electric heaters. Spark-ignition of a combustible gas mixture rapidly ele- 
vates the pressure and temperature within the vessel. The spray event (i.e., fuel injection) takes place when the desired thermodynamic conditions are achieved after a short cool-down period. These experiments used a commonrail diesel fuel injector equipped with a single 90- $\mu m$ diameter orifice (\# 370) belonging to the family of Spray A ECN injectors. Some initial and boundary conditions are listed in Table 1.

Table 1: Spray A experimental initial and boundary conditions

\begin{tabular}{ll}
\hline Fuel & n-dodecane \\
Fuel temperature $(\mathrm{K})$ & 363 \\
Nominal nozzle-hole diameter $(\mu \mathrm{m})$ & 90 \\
Common-rail pressure (bar) & 1500 \\
Injection duration $(\mathrm{ms})$ & $6(\mathrm{exp}), 1.5(\mathrm{sim})$ \\
Nozzle discharge coefficient & 0.89 \\
Ambient density $\left(\mathrm{kg} / \mathrm{m}^{3}\right)$ & 22.8 \\
Ambient $\mathrm{O}_{2}(\%)$ & $15^{a}$ \\
Ambient temperature $(\mathrm{K})$ & $800-1200$ \\
\hline
\end{tabular}

${ }^{a}$ Mole fraction.

Ignition delay times were measured using a high-speed camera operating at 20,000 frames per second. The camera was equipped with a 600 -nm short pass filter to suppress the high-intensity soot luminosity, which permits collection over the camera's dynamic range. Quasi-steady lift-off lengths based on excited state $\mathrm{OH}\left(\mathrm{OH}^{*}\right)$ emission were measured by an intensified CCD camera equipped with a $308 \mathrm{~nm}$ (10 nm FWHM) bandpass filter. Timeresolved soot extinction images were obtained using a diffused, ultra-fast 
light-emitting diode (LED) setup with a second high-speed camera. The details of the extinction imaging experiment can be found in Manin et al. [31].

\section{Computational setup}

Fuel spray and combustion simulations were performed using the traditional Lagrangian-parcel Eulerian-fluid approach in the CFD software CONVERGE [32-34]. It incorporates models for spray injection, atomization and breakup, turbulence, droplet collision, and coalescence. The gas-phase flow field is described by using the Favre-averaged Navier-Stokes equations in conjunction with the LES-based turbulence models. The turbulence model includes source terms for the effects of dispersed phase on gas-phase turbulence. These equations are solved by using a finite volume solver. The details of these models can be found in a previous publication [35], so only a brief description is provided here.

\subsection{Spray and combustion models}

The dispersed phase is modeled using a traditional Lagrangian parcel method. The Kelvin-Helmholtz (KH) and Rayleigh-Taylor (RT) models are used to predict the droplet breakup $[36,37]$. Droplet collisions are modeled with no time counter (NTC) algorithm [38]. A droplet evaporation model based on the Frossling correlation is used [39]. Also adopted is a dynamic drag model based on the postulation that the drag coefficient depends on the shape of the droplet, which can vary between a sphere and a disk [40].

Chemical kinetic modeling is performed using a $\delta$ function combustion model $[33,34,41]$ that directly couples with the gas-phase calculations. 
The effect of turbulence-chemistry-interaction (TCI) can be considered to be treated as a $\delta$ function PDF. This treatment has been demonstrated to perform well to simulate diesel spray flame in the context of RANS in the previous ECN workshops [12] and is expected to show promising predictions for LES models as well. This is mainly because the intense mixing at diesel engine conditions probably makes the reaction zones relatively broader, which making the $\delta$ function a reasonable assumption. However, the importance of TCI to simulate diesel spray flames in the context of LES needs to be evaluated and will be an interesting area to explore. An n-dodecane reduced chemical kinetic mechanism is implemented in the combustion simulations which consists of 103 species and 370 reactions. This mechanism has been previously developed and validated for ECN applications by Luo et al. [42]. A multi-zone model [43] is used to accelerate the chemistry calculations. Soot is modeled using an empirical Hiroyasu-based model [44] with $\mathrm{C}_{2} \mathrm{H}_{2}$ as the soot precursor.

\subsection{Subgrid turbulence model}

In the dynamic structure LES model, velocity and other thermodynamic variables are expressed in Favre form, whereas density and pressure are expressed in Reynolds form. The density-weighted LES spatial-filtering operation on the Navier-Stokes equation results in the filtered momentum equation:

$$
\frac{\partial \bar{\rho} \widetilde{u}_{i}}{\partial t}+\frac{\partial \bar{\rho} \widetilde{u_{i}} \widetilde{u}_{j}}{\partial x_{j}}=-\frac{\partial \bar{P}}{\partial x_{i}}-\frac{\partial \bar{\rho} T_{i j}}{\partial x_{j}}+\frac{\partial}{\partial x_{j}}\left(\mu \frac{\partial \widetilde{u_{i}}}{\partial x_{j}}\right)-\overline{F_{i}}
$$

where the LES sub-grid scale tensor:

$$
T_{i j}=\left(\widetilde{u_{i} u_{j}}-\widetilde{u_{i}} \widetilde{u_{j}}\right)
$$


is modeled using a one-equation dynamic structure model $[45,46]$. The transport equation for the sub-grid kinetic energy is given as follows:

$$
\frac{\partial \bar{\rho} k}{\partial t}+\frac{\partial \bar{\rho} k \tilde{u}_{j}}{\partial x_{j}}=\frac{\partial}{\partial x_{j}}\left(\frac{\mu}{P r_{s g s}} \frac{\partial k}{\partial x_{j}}\right)+\tau_{i j} \overline{S_{i j}}-\rho \epsilon
$$

where

$$
\overline{S_{i j}}=\frac{1}{2}\left(\frac{\partial \widetilde{u_{i}}}{\partial x_{j}}+\frac{\partial \widetilde{u_{j}}}{\partial x_{i}}\right)
$$

and the sub-grid kinetic energy $k$ is

$$
k=\frac{1}{2}\left(\widetilde{u_{i} u_{j}}-\widetilde{u_{i}} \widetilde{u_{j}}\right)
$$

and the sub-grid dissipation rate $\epsilon$

$$
\epsilon=C_{\epsilon} \frac{k^{1.5}}{\Delta}
$$

where $C_{\epsilon}$ is a model constant with value of 1.0 and, $\Delta=V_{\text {cell }}^{1 / 3}$.

The sub-grid stress tensor is modelled by:

$$
\tau_{i j}=2 k \bar{\rho} \frac{L_{i j}}{L_{k k}}
$$

where the Leonard stress tensor is defined as:

$$
L_{i j}=\widehat{\widetilde{u_{i}}} \overline{u_{j}}-\widehat{\widetilde{u_{i}}} \widehat{\widetilde{u_{j}}}
$$

where " $\wedge$ " represents a test-level filter which is created from the center cell and the neighbor cells in the current study.

\subsection{Mesh details}

The code uses an innovative, modified cut-cell Cartesian method for grid generation $[33,34]$. The base grid size is $1 \mathrm{~mm}$. In order to resolve the 
flow near the injector, a fixed grid embedding is employed such that the minimum grid size is $0.0625 \mathrm{~mm}$. Apart from this region, it is rather difficult to determine a priori where a refined grid is needed. Hence, adaptive mesh refinement is employed for the velocity, temperature, and species fields and leads to a minimum cell size of $0.0625 \mathrm{~mm}$. A RANS based method is also used for comparison with the LES results in this study and has a minimum grid size of $0.25 \mathrm{~mm}$. Based on previous studies by Xue et al. [16] and Senecal et al. [46] for non-reacting flow, these resolutions for LES and RANS calculations were found to be grid convergent (for this case) and resulted in a reasonable compromise between accuracy and computational cost. The peak cell count of a typical LES case is about 22 million while for the RANS case is about $140 \mathrm{~K}$ at $1 \mathrm{~ms}$. The mesh details on the cross section along the spray axis is presented in Fig. 1. The contour is colored by an $\mathrm{OH}$ mass fraction. It can be observed that there are roughly $6-10$ cells across the $\mathrm{OH}$ mass fraction layer in the downstream thin flame region. Analysis of the Kolmogorov length scale suggests that it is on the order of 1 to $5 \mu \mathrm{m}$ in the downstream flame region, highlighting the importance of investigating the subgrid effect.

\section{Results and discussion}

\subsection{Mesh resolution study}

A systematic mesh resolution study is conducted in this section, as shown in Fig. 2, where mixture fraction $(\mathrm{Z})$, temperature $(\mathrm{T}), \mathrm{OH}$, and soot mass fraction are presented with different mesh resolutions from $0.5 \mathrm{~mm}$ to 0.0625 mm, respectively. From Fig. 2(a), we can see significantly different struc- 


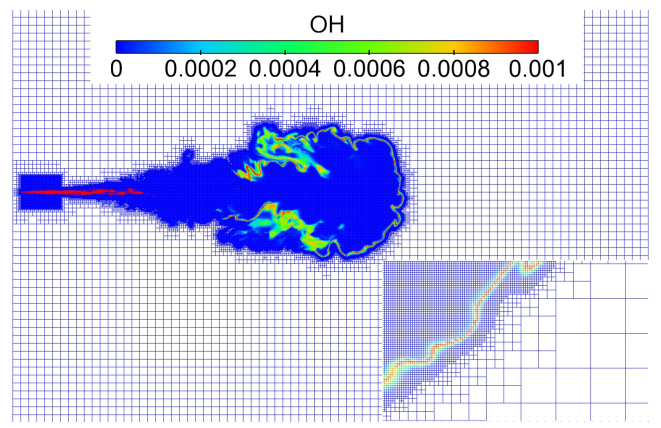

Figure 1: Cut-plane mesh with $\mathrm{AMR}$ and $\mathrm{OH}$ mass fraction along the spray axis at $1 \mathrm{~ms}$ for the $900 \mathrm{~K}$ ambient temperature condition.

tures of the mixture fraction with different mesh resolutions. With coarse mesh resolutions, the spray flames penetrate further downstream due to the under-resolution of the mixing field and spray momentum exchange. Refining the mesh resolution results in finer flow structures captured by the LES calculations. Decreasing the cell size down to $0.0625 \mathrm{~mm}$, it can be seen that the difference in mixture fraction results between $0.090 \mathrm{~mm}$ and $0.0625 \mathrm{~mm}$ becomes subtle. This indicates that the mesh with a minimum cell size of $0.0625 \mathrm{~mm}$ might be close to grid convergence. In addition, previous studies of non-reacting sprays at the same ECN conditions [16, 47] suggest the minimum cell size of $0.0625 \mathrm{~mm}$ is sufficient. Of course, it would be interesting to obtain a set of results with an even higher mesh resolution to compare with Fig. 2. However, this will be a future study due to the fact that the computational cost will be substantially higher.

The same trends were also observed for the other three scalars, as shown in Fig. 2. For example, the lift-off locations and the thickness of the flame downstream are vastly different with different mesh resolutions as depicted in Fig. 2(c). For soot predictions reported in Fig. 2(d), the shape and location of 


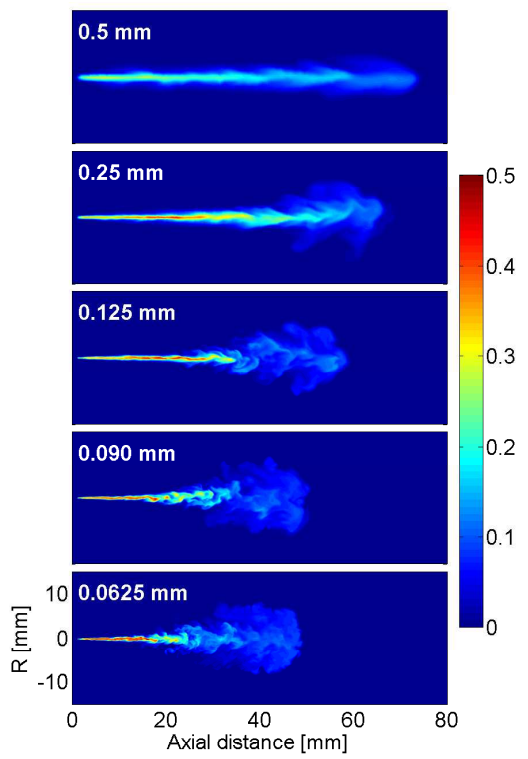

(a) Z

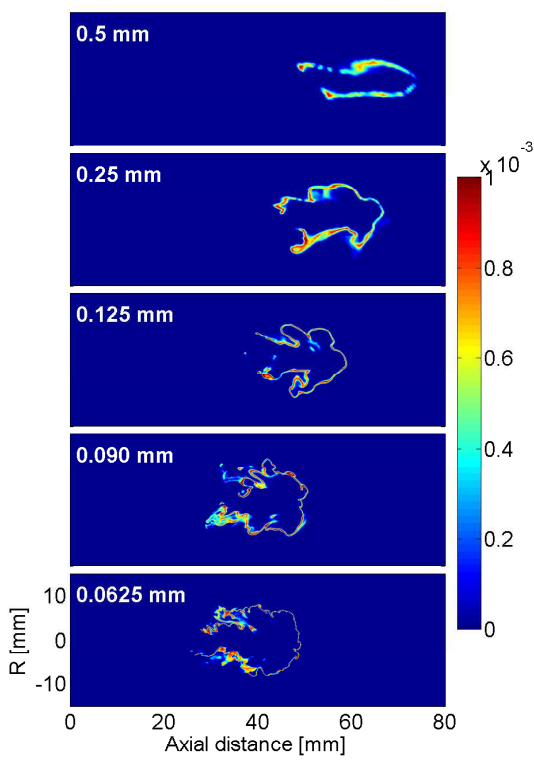

(c) $\mathrm{OH}$

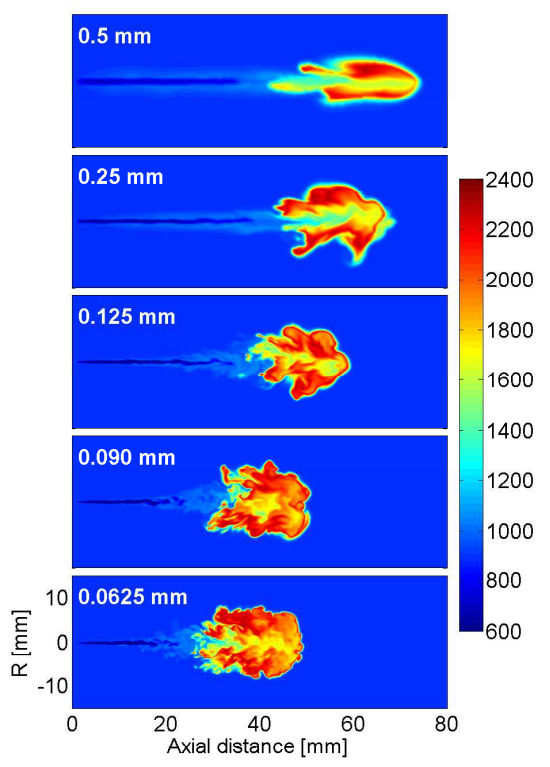

(b) $\mathrm{T}$

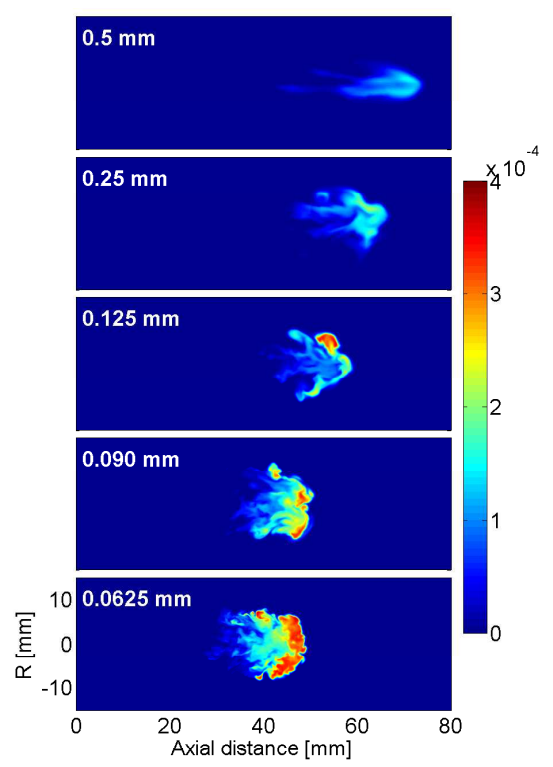

(d) Soot

Figure 2: Comparison of cross section of (a) Z, (b) T, (c) OH, and (d) soot mass fraction at $1 \mathrm{~ms}$ along the spray axis with different mesh resolutions at the $900 \mathrm{~K}$ ambient temperature condition. 
the soot cloud are quite different at coarser resolutions. More interestingly, the magnitude of the soot mass fraction is substantially lower at coarser meshes compared to the finer meshes. This observation is mainly due to the precursor specie $\mathrm{C}_{2} \mathrm{H}_{2}$, which is more unresolved in the lower mesh resolution. With a higher mesh resolution, the soot cloud is more upstream and the magnitude of the soot mass fraction is higher. This at least indicates that a well-resolved mixing field can result in a mesh-convergent emission prediction. The mesh resolution with a minimum cell size of $0.0625 \mathrm{~mm}$ is used for the following studies since the scalar fields tend to grid converge at this resolution based on current spray flame and past non-reacting studies [16].

Figure 3 presents the comparison of ignition delay predictions with different mesh resolutions compared against experimental measurements at different ambient temperature conditions. The ignition delay $\left(\tau_{i d}\right)$ from the simulation is defined as the time from start of injection (SOI) to the time where the maximum rate of maximum temperature rise in the domain occurs $[14,15]$ :

$$
\tau_{i d}=\tau_{\left(\frac{d T_{\max }}{d t}\right)}-\tau_{S O I}
$$

where $T_{\max }(t)=\max (T(x, y, z, t))$ and $\tau_{S O I}$ is the time at SOI. There are small differences in ignition delay with different mesh resolutions. We consider these differences to be small since the variation in ignition delay from realization to realization is higher than this, as shown later. The simulations can capture the experimental trend very well, i.e., with higher ambient temperatures the ignition delay decreases. The quantitative results are also very good across the ambient temperature range considered, except for the $800 \mathrm{~K}$ 
ambient temperature case. This over-prediction is attributed to the lack of accuracy in the chemical kinetic mechanism under this condition, which has been reported by several studies [17, 18, 22, 42].

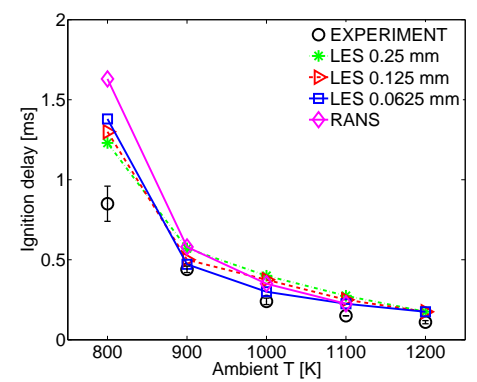

Figure 3: Comparison of predicted ignition delay with different LES mesh resolutions, RANS and the measurements at different ambient temperature conditions. The error bars show the experimental uncertainty obtained from [12].

\subsection{Temporal evolution of the flame}

Figure 4 shows the temporal evolution of mixture fraction and temperature between LES and RANS for the $900 \mathrm{~K}$ ambient temperature condition. It is noted that while all the other are the same between LES and RANS, the timing of the third row is selected to be different so as to depict the main ignition timing from LES and RANS calculations. We define first-stage ignition as events where the temperature rise is less than $400 \mathrm{~K}$ above the ambient temperature, to distinguish it from main, high-temperature ignition at higher temperatures. The black lines in the temperature contours shown in Figs. 4(b) and 4(d) represent the stoichiometric mixture fraction $\left(Z_{s t}=\right.$ 0.045). Significant fluctuations of mixture fraction and temperature fields are observed for the LES predictions compared to those of RANS at different timings, which may result in different ignition behavior between RANS 
and LES. This will be examined in detail later. It is also interesting to note that the $Z_{s t}$ line crosses the middle of the high temperature zone for RANS (moves closer to centerline, overlapping more of the high temperature field), while the line for LES is located at the edge of the flame where the highest temperature regions exist. The fundamental reason is that LES is a singlerealization simulation although it is space-averaged and therefore, the flame is very thin due to the fine mesh resolution. While RANS is a time-averaged simulation ("ensemble-averaged"), which thickens the flame and moves the $Z_{s t}$ line to the middle of the flame. The ensemble-averaged LES results shown in Fig. 10 demonstrate this observation.

After studying the transient processes spatially, we examine the temporal evolution of scatter plot of temperature in mixture fraction space to understand the ignition behavior, which is presented in Fig. 5. For both LES and RANS, the first row shows the scatter plot before ignition happens and all the points cluster around the mixing line. Around $0.32 \mathrm{~ms}$ (in the second row), the first stage ignition is observed. Then moving to the third row, main ignition happens at $0.54 \mathrm{~ms}$ for RANS and $0.44 \mathrm{~ms}$ for LES, both still in the rich mixture. It is interesting to note here that RANS presents a smooth transition of different temperatures at different mixture fractions. On the other hand, LES exhibits an abrupt transition in the mixture fraction space for certain temperatures during the main ignition stage. This is due to the single LES realization that could exhibit abrupt transition in the ignition process. However, RANS ("ensemble-average") tends to smooth out this apparent abrupt transition. The second stage ignition for LES favors a mixture fraction less than 0.14. The temperature continues to increase (shown in 


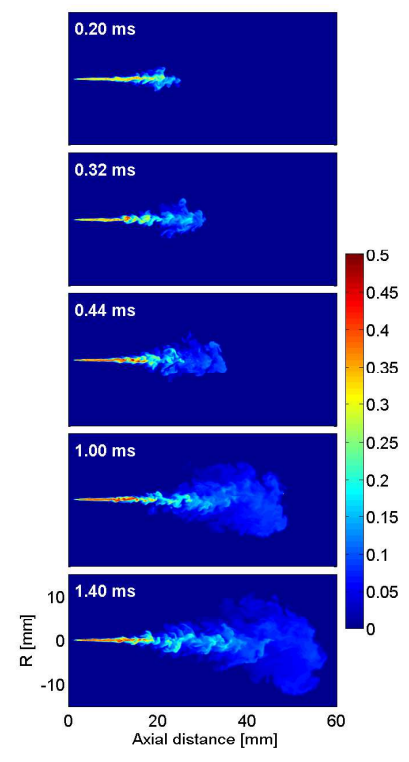

(a) Z, LES

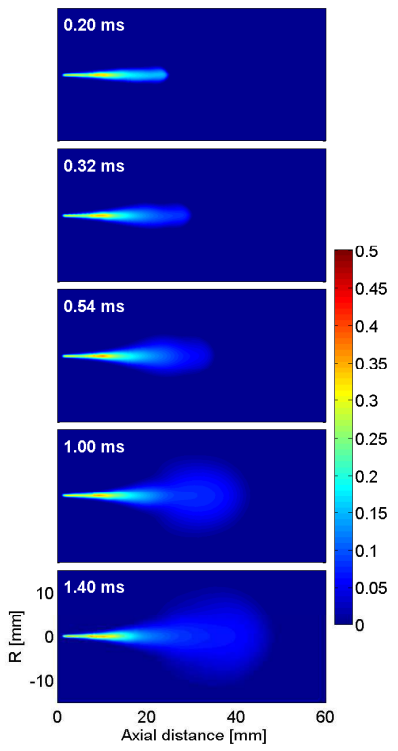

(c) Z, RANS

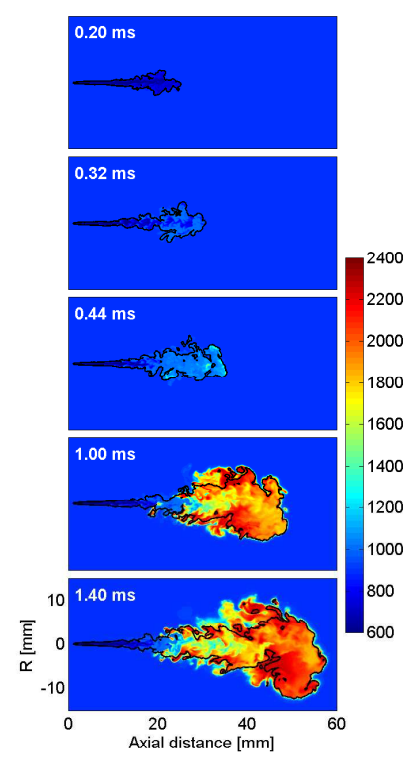

(b) T, LES

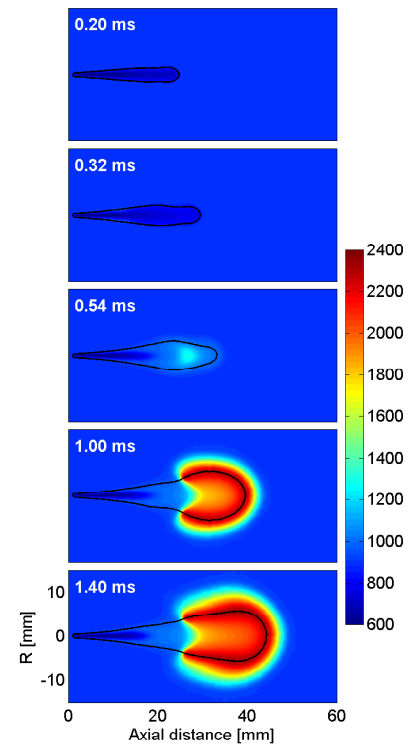

(d) T, RANS

Figure 4: Temporal evolution of (a) Z and (b) T for LES, and (c) Z and (d) T for RANS on the cross sections along the spray axis, at $900 \mathrm{~K}$ ambient temperature condition. The black line is the stoichiometric mixture fraction contour. 


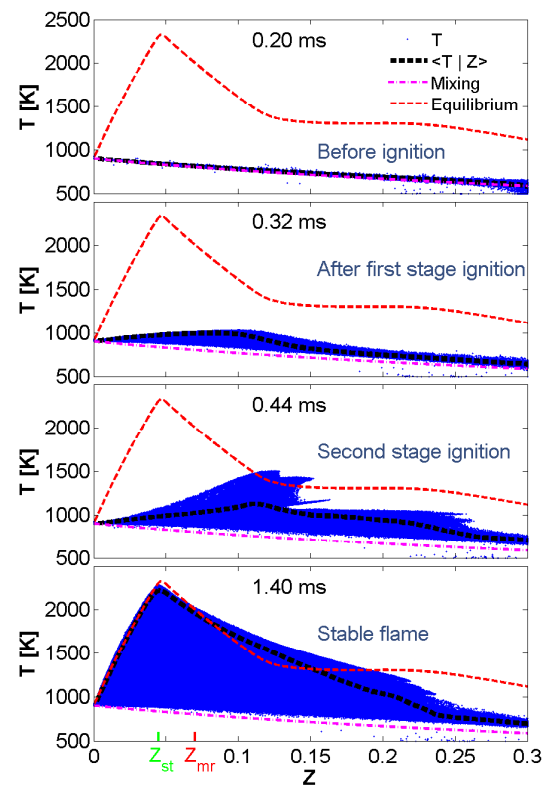

(a) LES

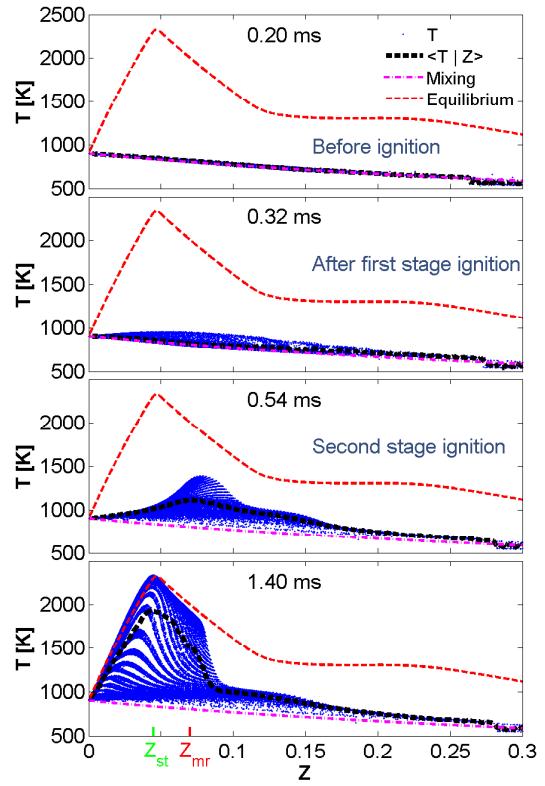

(b) RANS

Figure 5: Temporal evolution of scatter plot of temperature versus mixture fraction between (a) LES and (b) RANS for $900 \mathrm{~K}$ ambient temperature condition. The pink line is the adiabatic mixing line of pure liquid fuel and ambient oxidizer, the red line is the equilibrium line, and the black line is the mean temperature conditional on the mixture fraction. $Z_{s t}$ is the stoichiometric mixture fraction and $Z_{m r}$ is the most reactive mixture fraction obtained from a homogeneous constant-pressure reactor. 


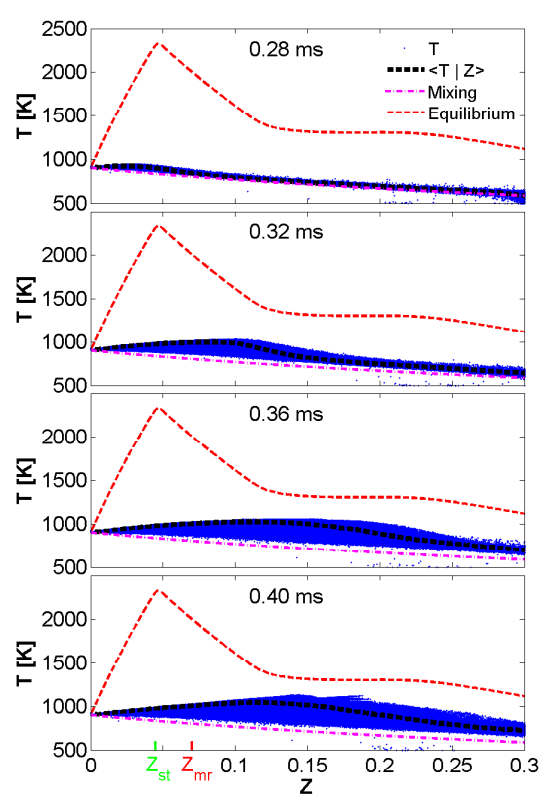

(a) First stage

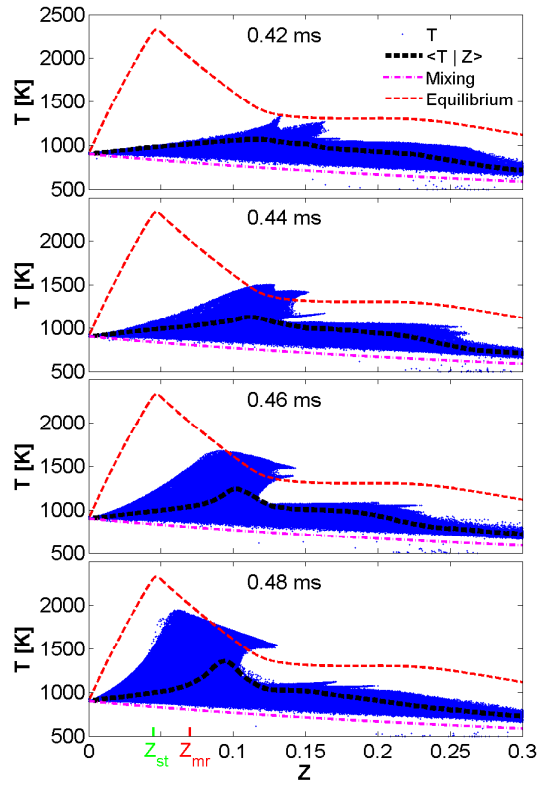

(b) Second stage

Figure 6: Scatter plot of temperature in mixture fraction space during (a) first stage and

(b) second stage ignitions at $900 \mathrm{~K}$ ambient temperature condition. The pink line is the adiabatic mixing line of pure fuel and ambient oxidizer and the red line is the equilibrium line, and black line is the mean temperature conditional on mixture fraction. 


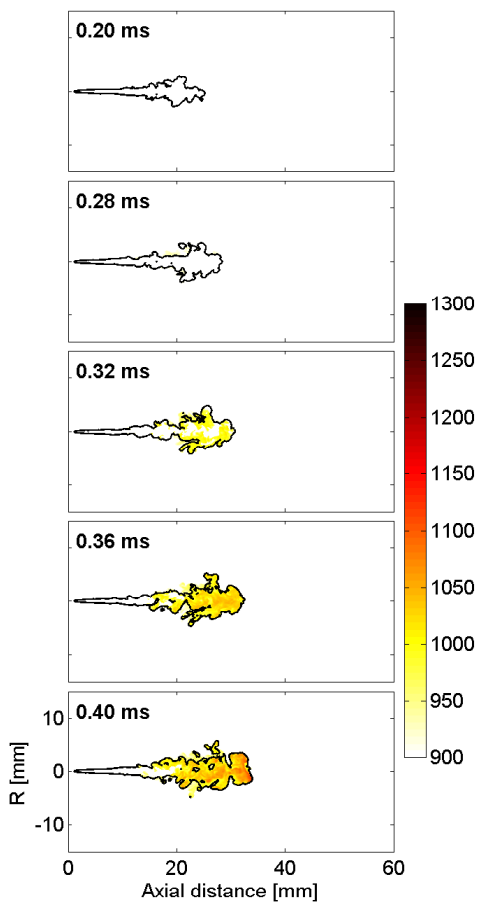

(a) First stage

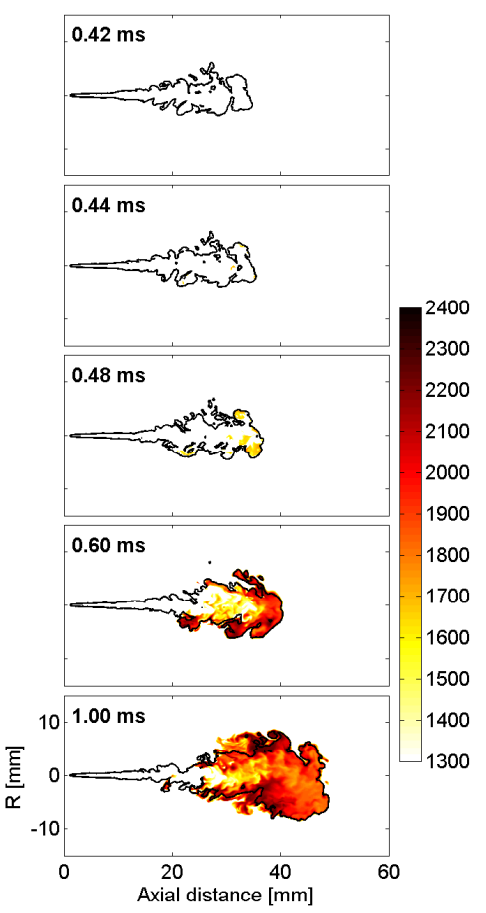

(b) Second stage

Figure 7: Contour plot of temperature during (a) first stage and (b) second stage ignitions at $900 \mathrm{~K}$ ambient temperature condition. The black line represents $Z_{s t}$. 
the fourth row) and the mean temperature becomes close to the equilibrium state. The peak temperature is at the stoichiometric mixture fraction, as expected, and the high temperature regions expand to very lean and also very rich mixtures. It is noted that the mean temperature of the fourth row for RANS has not reached the equilibrium state due to the late ignition.

Further analysis of the ignition process in mixture fraction space shown in Fig. 5 is conducted, where the first- and second-stage ignition events are extracted and shown in Fig. 6(a) and 6(b), respectively. First, looking at the first-stage ignition shown in Fig. 6(a), the ignition first initiated in a very lean mixture (leaner than $Z_{s t}$ ) with minimal heat release and "propagates" to a rich mixture, richer than $Z_{m r}$ until $0.4 \mathrm{~ms}$. This lean mixture ignition is presumably due to the higher local temperature and then, promotes the low temperature reactions in the rich mixture due to the transport of warmer lean products into rich mixtures. The observation that first-stage ignition initiates under more fuel-lean conditions is consistent with the findings of Skeen et al. [30, 48]. Just after $0.4 \mathrm{~ms}$, shown in Fig. 6(b), higher temperature cells occur in a very rich mixture with a mixture fraction from 0.12 to 0.15 , and "propagate" back to a relatively less-rich mixture. It is interesting to notice the different patterns in scattering during the second stage ignition. This is feasible during the flame ignition process as some pockets can ignite earlier and others may ignite later even though they have similar mixture fraction values. This indicates that some fluid parcels with similar mixture fractions encounter widely differing scalar dissipation rates (around 800 to 5 $\mathrm{s}^{-1}$ at $\mathrm{Z}_{s t}$ from the region close to the nozzle exit to the downstream region), for example, where the cumulative mixing rate history could cause either 
earlier or later ignition (sometimes by as much as a factor of $2-3$ times the homogeneous ignition delay).

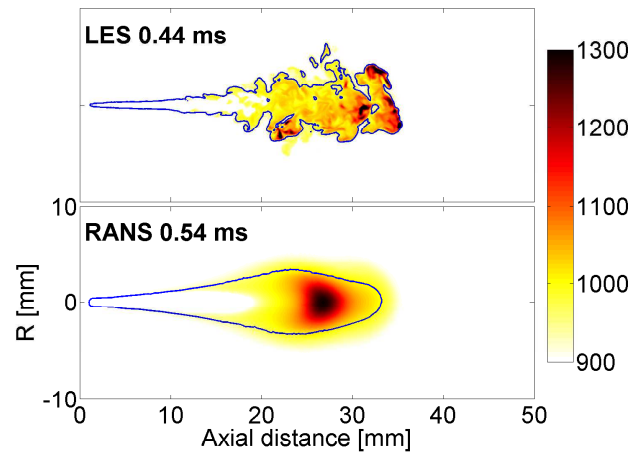

Figure 8: Ignition location comparison between RANS and LES at $900 \mathrm{~K}$ ambient temperature condition. The solid blue line represents the stoichiometric mixture fraction.

Corresponding to Fig. 6, the ignition events in space are also depicted in Fig. 7 at the same timing. At $0.28 \mathrm{~ms}$ in Fig. 7(a), a slight temperature increase is observed at the outer edge of the flame $\left(Z_{s t}\right)$ around $20 \mathrm{~mm}$, which indicates the first stage ignition initiates in lean mixture and is consistent with the scatter plot shown in Fig. 6(a). Then, the temperature slightly increases, and the higher temperature region expands and penetrates into a more fuel-rich mixture (inside of the $Z_{s t}$ contour) at $0.32 \mathrm{~ms}$. Then moving forward to $0.4 \mathrm{~ms}$, the higher temperature $(\sim 1050 \mathrm{~K})$ region exists entirely inside the $Z_{s t}$ contour. Figure $7(\mathrm{~b})$ sets the temperature threshold of $1300 \mathrm{~K}$ (400 K above the ambient) to show the second stage ignition. At $0.44 \mathrm{~ms}$, it is clearly seen that several ignition spots are observed inside the rich mixture region, and these spots expand and finally connect at a later stage.

The main ignition is extracted and examined in Fig. 8, which depicts the temperature contours for LES at $0.44 \mathrm{~ms}$ and RANS at $0.54 \mathrm{~ms}$, respectively. 


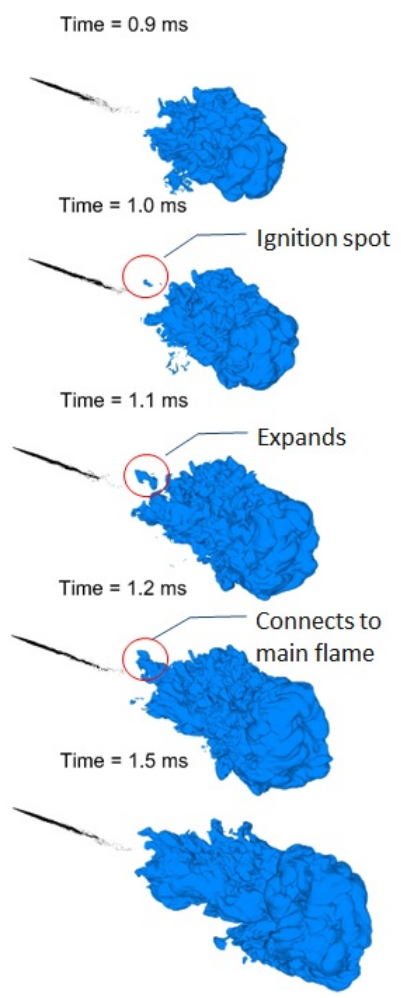

Figure 9: Transient flame development colored by temperature for the $900 \mathrm{~K}$ ambient temperature condition. 
For RANS, there is only one ignition spot on the centerline of the flame, located just behind the head of the flame and rich of stoichiometric mixture fraction. This ignition behavior in RANS context has been analyzed by Pei et al. $[49,50]$ in detail, which suggests that the ignition location is essentially controlled by a straining effect and prefers lower scalar gradient regions. However, for the ignition predictions of LES, several ignition spots can be noticed due to the fluctuation of the mixing field. The ignition spots are also in a rich mixture, but close to the stoichiometric mixture fraction contour. This picture is also physically more realistic when compared with experiments [51].

Another interesting phenomenon that can be observed to some extent is the flame stabilization mechanism. In Ref. [50], a study of implied convection, diffusion, and reaction (CDR) terms has suggested that the flame stabilization mechanism is auto-ignition controlled, but modulated by flame propagation. In Fig. 4(b), one can notice that there is an ignition spot upstream of the flame, from the temperature contour at $1 \mathrm{~ms}$ of LES. It initiates at $1 \mathrm{~ms}$, expands and finally connects to the main flame before $1.4 \mathrm{~ms}$. This can be further illustrated by Fig. 9, where the flame is colored by a temperature of $1300 \mathrm{~K}$ from $0.9 \mathrm{~ms}$ to $1.5 \mathrm{~ms}$. Although the flame is not at the quasi-steady state yet, the flame stabilization location is almost stable. One can see from the plot that there is an ignition spot clearly initiated at 1.0 ms upstream of the flame that expands at $1.1 \mathrm{~ms}$ and connects to the main flame base at $1.2 \mathrm{~ms}$. The growing upstream ignition kernel is the result of ignition and flame propagation processes, but as the event was initiated by auto-ignition, the lift-off stabilization itself can be controlled by auto- 
ignition. This direct observation from LES simulations supports the analysis with the CDR method in [50].

\subsection{Realization variations}

Following the examination of the transient ignition processes, the variation with different LES realizations, ensemble-average of 16 realizations, and RANS predictions are presented to qualitatively study the differences between the LES and RANS models, and also to quantify the differences between LES realizations. Figure 10 shows the fields of mixture fraction,

temperature, $\mathrm{OH}$, and soot comparison on the cross section along the spray axis between different LES realizations, ensemble-averaged 16 LES realizations, and RANS predictions at $1 \mathrm{~ms}$ for the $900 \mathrm{~K}$ ambient temperature condition. It is clearly observed that the RANS simulation presents a smooth structure of the flame with axis-symmetric features for each of the scalars. However, the LES shows a completely different picture with an asymmetric flame structure clearly observed for all the different LES realizations. For example, the temperature predicted by a single LES realization shows substantial fluctuation as presented in Fig. 10(b), while the ensemble-average of 16 realizations shows a much smoother contour like RANS. However, the distribution of the temperature is still quite different when comparing the ensemble-averaged LES with RANS. Ensemble-averaged LES results show a higher-temperature region around $40 \mathrm{~mm}$ downstream away from the spray axis and relatively low-temperature regions around the flame lift-off region and the leading flame region close to the spray axis. The predictions of RANS present similar temperature magnitude along the stoichiometric mixture fraction line. However, we acknowledge the fact that the jet penetration 
is different for the RANS and LES predictions, which will have some influence on the flame locations and temperature distributions. Figure 11 shows the root mean square (RMS) of temperature at $1 \mathrm{~ms}$ for the 16 LES realizations at the $900 \mathrm{~K}$ ambient temperature condition. It can be seen that a higher variability occurs on the edge of the flame in the lean mixture region and much lower variability is found inside the flame. This is probably due to the strong turbulence on the edge of the spray flame.

Another interesting observation is that the stoichiometric mixture fraction line moves from the edge to the middle of the flame when ensemble-averaging the LES realizations, similar to the finding of RANS. Secondly, the $\mathrm{OH}$ contour in the upstream of LES predictions as shown in Fig. 10(c) is relatively thick compared to the downstream $\mathrm{OH}$ layer due to the thickening of the flame by the intense turbulence. On the other hand, the $\mathrm{OH}$ contour predicted by RANS shows an equally thick flame layer across the domain with a high concentration in the middle of the flame. Thirdly, the predictions of soot by LES as shown in Fig. 10(d) shows a much broader region with a much higher concentration in the leading flame further downstream compared to that by RANS. This aspect will be examined for more details later. Another interesting phenomenon is the ensemble-averaged $\mathrm{OH}$ shown in Fig. 10(c) which shows a similar observation to experiments [12], i.e., higher concentration regions near the flame stabilization location with low concentration downstream. The realization variation was also examined in the mixture fraction space and only a very subtle difference was observed, therefore it not shown here. Overall, since the mixing field is better resolved with the LES calculations, the predictions are expected to be both quantitatively and 


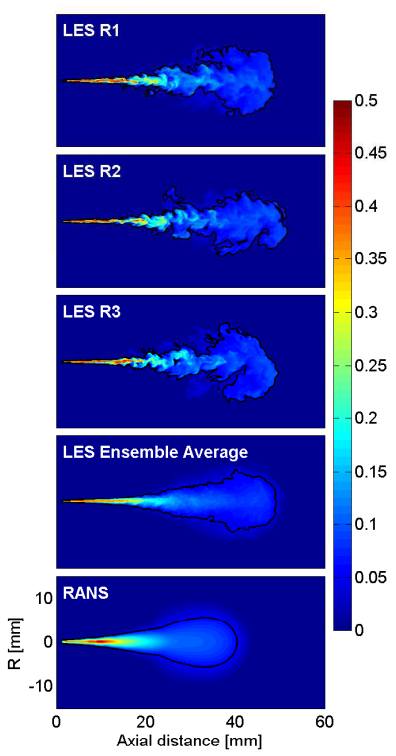

(a) Z

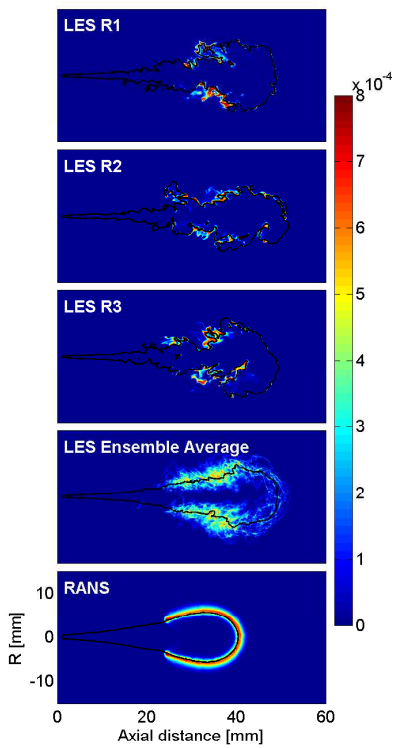

(c) $\mathrm{OH}$

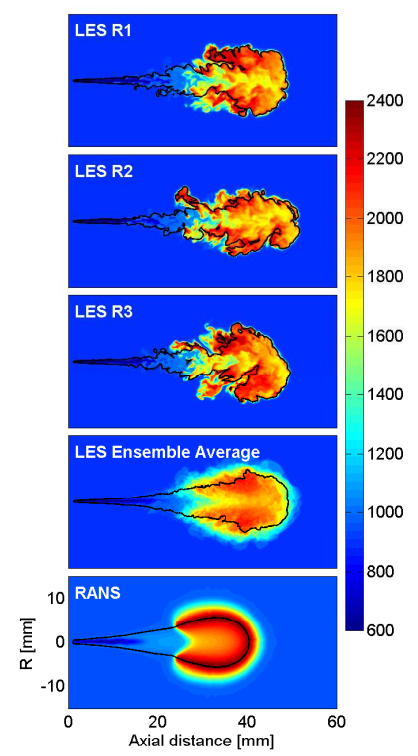

(b) $\mathrm{T}$

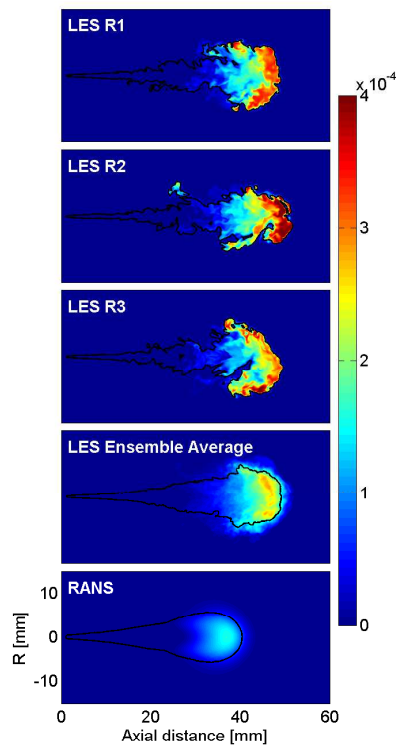

(d) Soot

Figure 10: Realization to realization variation, ensemble average of 16 LES calculations and RANS results of (a) Z, (b) T, (c) OH, and (d) soot on the cross section along the spray axis at $1 \mathrm{~ms}$ for the $900 \mathrm{~K}$ ambient temperature condition. The black line represents the stoichiometric mixture fraction. 


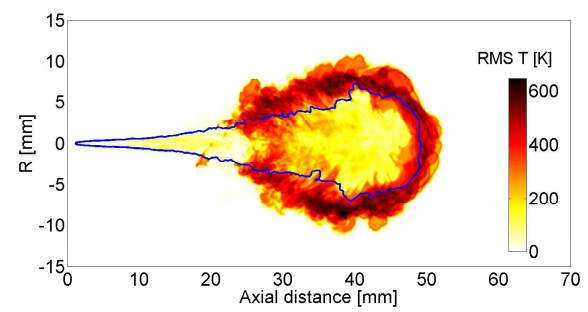

Figure 11: RMS temperature of 16 LES realizations at $1 \mathrm{~ms}$ at the $900 \mathrm{~K}$ ambient temperature condition. The blue solid line represents the stoichiometric mixture fraction.

qualitatively better than RANS.

\subsection{Temperature variation}

Figure 12 reports the ambient temperature variation of mixture fraction, temperature, $\mathrm{OH}$, and soot on the cross section along the spray axis. It is noted that all the reported results in this section are from a single LES realization. The mixture fraction contour in Fig. 12(a) shows a similar penetration length, as expected under constant ambient density. From Fig. 12(b), one can clearly see that the flame becomes narrower with the increasing ambient temperature, which agrees with the observations in the experiments. The maximum temperature is obviously higher with higher ambient temperature conditions. It is noted that the $800 \mathrm{~K}$ case has not ignited yet at this timing. The $\mathrm{OH}$ contour is depicted in Fig. 12(c) for different ambient temperatures. Obviously, the flame lift-off location is closer to the injector with higher ambient temperatures. One interesting observation here is that the thick flame regions are roughly at the same locations for different conditions, i.e., around $40 \mathrm{~mm}$. This is further examined in Fig. 13 by plotting the velocity vectors inside the flame contour for all the temperatures. This shows a typical spray flame behavior, i.e., the velocity vector peaks on the 


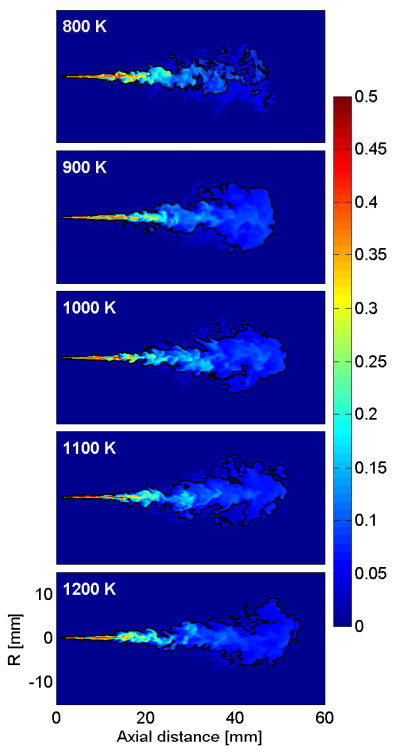

(a) Z

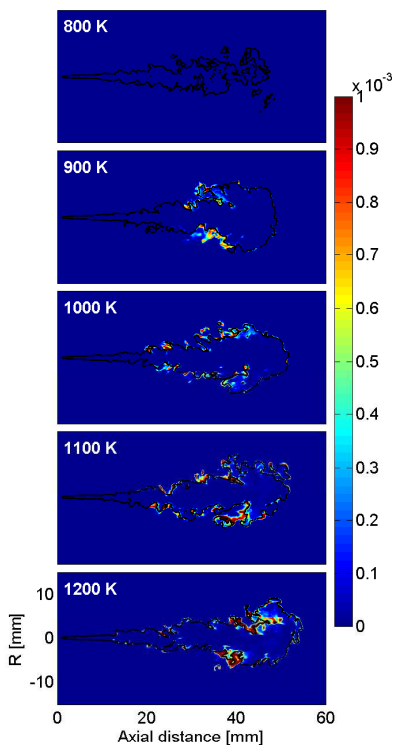

(c) $\mathrm{OH}$

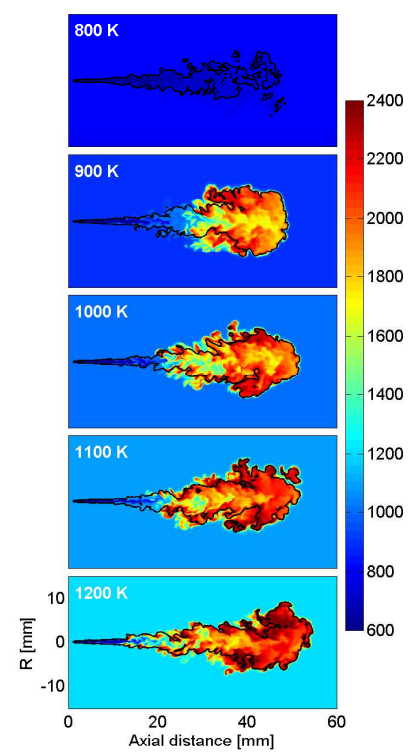

(b) $\mathrm{T}$

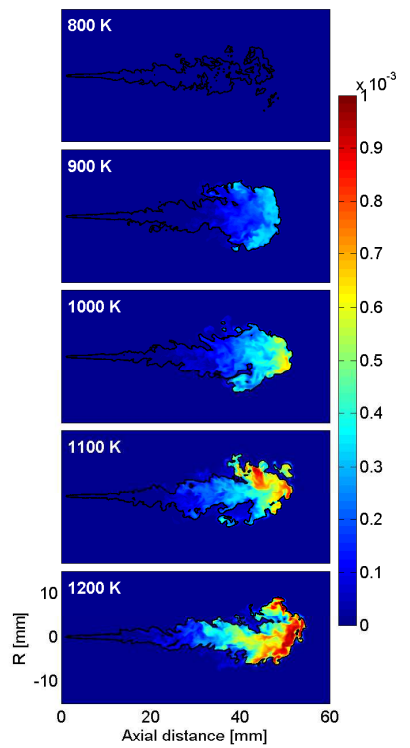

(d) Soot

Figure 12: Ambient temperature variation of (a) Z, (b) T, (c) OH, and (d) Soot on the cross section along the spray axis at $1 \mathrm{~ms}$. The black line represents the stoichiometric mixture fraction.
29 
spray axis and there is entrainment upstream of the flame lift-off location. One can also notice that there is a recirculation zone just upstream the head of the flame, which enhances the turbulence and thickens the flame in this region, i.e., around $40 \mathrm{~mm}$.

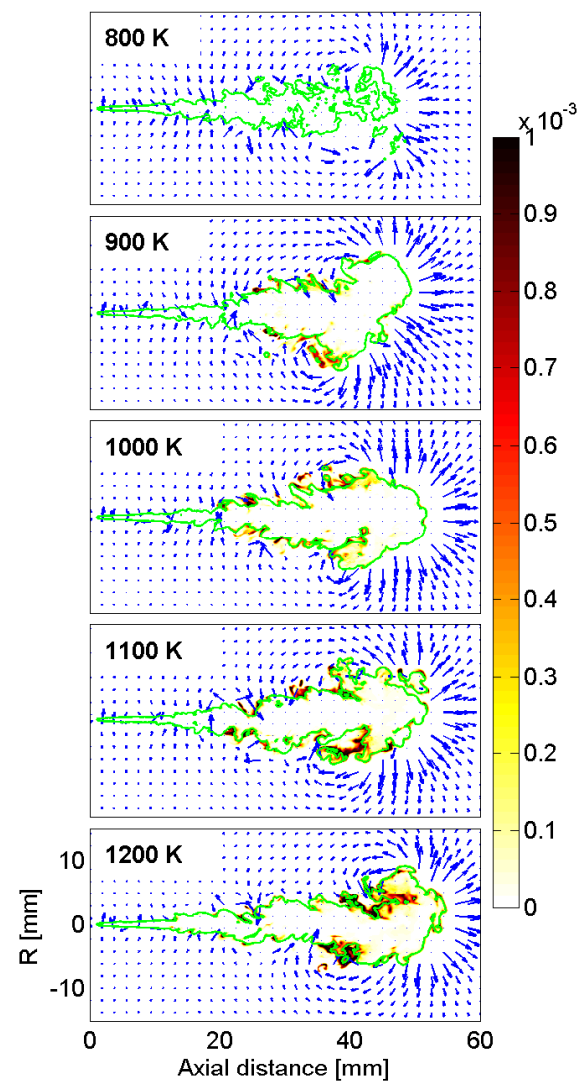

Figure 13: Flame colored by $\mathrm{OH}$ mass fraction on the cross section along the spray axis at $1 \mathrm{~ms}$ for different ambient temperature conditions. The arrows are the velocity vector with threshold $10 \mathrm{~m} / \mathrm{s}$. The green line is the stoichiometric mixture fraction.

The fields of soot on the cross section along the spray axis are shown in Fig. 12(d) for different ambient temperatures. It can be observed that the 


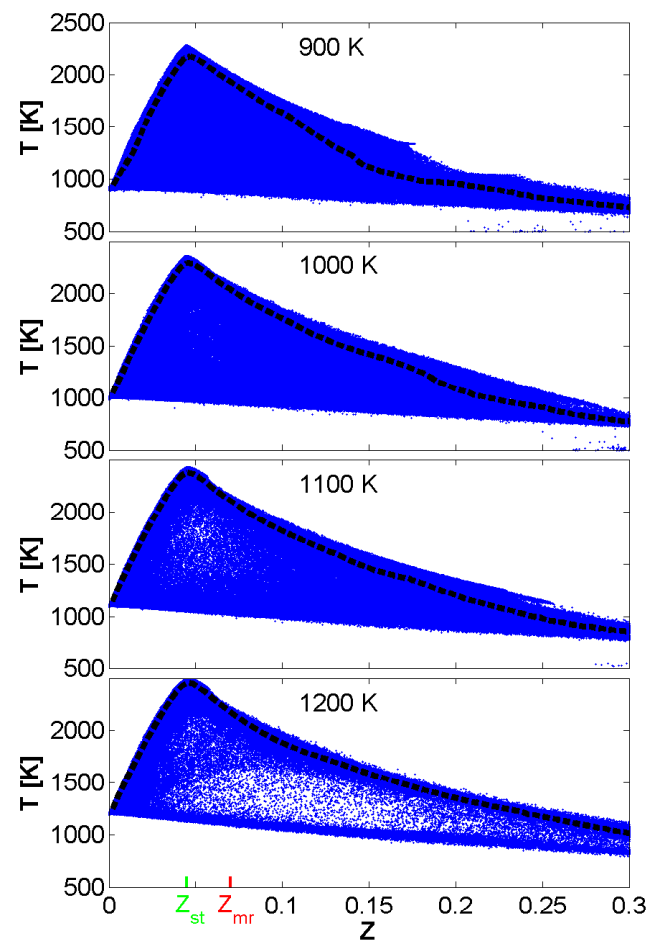

Figure 14: Scatter plot of temperature in the mixture fraction space at $1 \mathrm{~ms}$ for different ambient temperature conditions. The black dashed lines are the mean temperature conditional on mixture fraction.

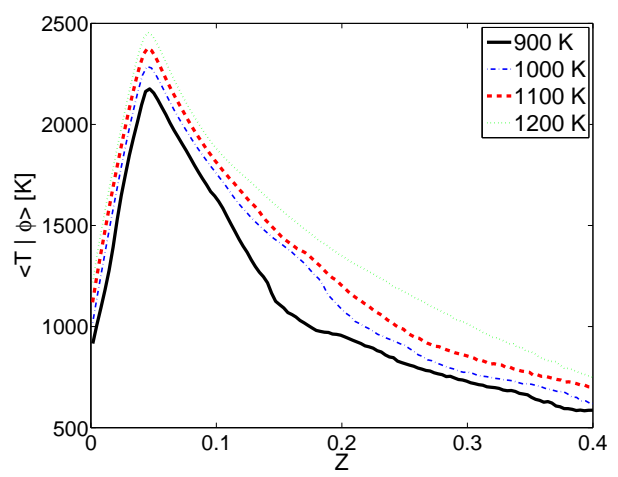

Figure 15: Mean temperature conditional on mixture fraction at $1 \mathrm{~ms}$ for different ambient temperature conditions. 
soot cloud is longer with higher concentration in higher ambient temperature conditions. The higher ambient temperature case ignites in a more fuel-rich region closer to the liquid length and therefore burns at a more fuel-rich equivalence ratio. The higher soot mass fraction is mainly due to the higher temperature in rich mixture, which is verified in Fig. 14. Figure 14 plots the temperature in mixture fraction space for different ambient temperature conditions. The black line is the mean temperature conditional on mixture fraction. One can see that the higher ambient temperature case has more scatters close to the equilibrium state. If we extract the mean temperature conditional on mixture fractions and plot them in Fig. 15, one can see that the mean temperature is higher for a higher ambient temperature case at a relatively richer mixture. This supports the observation that a higher ambient temperature has more soot mass fraction presented in Fig. 12(d).

\subsection{Ignition delay and lift-off length}

After qualitatively examining the flame structure at different ambient temperature conditions, the quantitative comparison of ignition delay and flame lift-off length from LES, RANS and the experiments are presented in Figs. 3 and 17, respectively. Lift-off length in the simulation is defined as the axial distance from the nozzle exit to the location of $14 \%$ of maximum $\mathrm{OH}$ mass fraction in the quasi-steady state [22]. To be more specific, the maximum value of $\mathrm{OH}$ mass fraction is first extracted from the quasi-steady state of the simulation, and then multiplied by $14 \%$ as a threshold for the $\mathrm{OH}$ specie to define the lift-off location. The threshold of $14 \%$ is based on a study of modeling Spray A using a chemical mechanism including the $\mathrm{OH}^{*}$ specie [22]. It was found that the lift-off length using $14 \%$ of maximum $\mathrm{OH}$ 
mass fraction was roughly equivalent to the one using $50 \%$ of $\mathrm{OH}^{*}$ levelingoff value. The sensitivity of lift-off length to the threshold was examined and is shown in Fig. 16, where 2\%, 14\%, and 50\% are compared. It can be seen that there are only subtle differences between different thresholds most of the time. This is mainly due to the high $\mathrm{OH}$ gradient near lift-off locations as shown in Fig. 10(c). However, the difference becomes significant at some timing, e.g., around $0.8-0.9 \mathrm{~ms}$, for $50 \%$ compared to $2 \%$ and $14 \%$. This implies the $\mathrm{OH}$ gradient becomes lower around this timing and makes the lift-off length more sensitive to the threshold used.

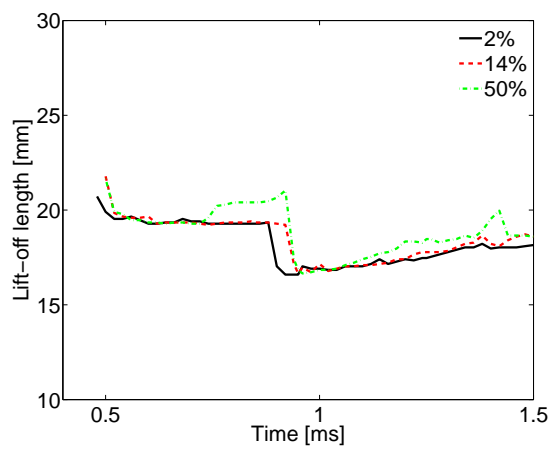

Figure 16: Temporal lift-off length for one LES realization with different $\mathrm{OH}$ thresholds at the $900 \mathrm{~K}$ condition.

For the ignition delay predictions in Fig. 3, both LES and RANS are capable of capturing the experimental trend of longer ignition delay for lower ambient temperatures. LES predictions are in excellent agreement with the experimental data from $900 \mathrm{~K}$ to $1100 \mathrm{~K}$, but over-predict at $800 \mathrm{~K}$ conditions. LES predictions are also better than RANS especially at lower ambient temperature cases. This is mainly due to the significant fluctuations in the mixture fraction space due to the LES model which increases the probability 
of igniting the mixture in certain regions which are richer than typically predicted by RANS. For higher ambient temperature conditions like 1100 K, no difference in the predictions between RANS and LES is found. Since both the turbulence models tend to over predict ignition delay at lower ambient temperatures, the need for better chemical kinetic mechanisms under low temperature conditions is highlighted. It should be noted that all the LES results are from a single realization except the $900 \mathrm{~K}$ condition, where 16 realizations are averaged.

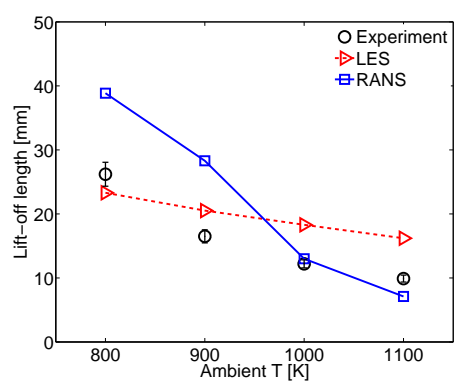

Figure 17: Comparison of predicted lift-off length between LES, RANS and measurements at different ambient temperature conditions. The error bars show the measurement uncertainty.

As for the lift-off length predictions in Fig. 17, both LES and RANS can also capture the experimental trend of longer lift-off length at lower ambient temperature conditions. The LES predictions are less sensitive to the ambient temperature. However, this cannot be over-interpreted because of the large variations of lift-off length for different realizations as shown in Fig. 23. LES gives better estimations at lower ambient temperature conditions, but worse at higher ambient temperature conditions compared to RANS. The reason for the worse predictions of lift-off length at higher ambient temperature 
conditions might be due to the insufficient number of realizations to get ensemble-averaged values at these conditions. This will be investigated in future studies. In fact, there is only one realization for each condition at the high temperature cases due to the computational cost. It is noted that there are 16 realizations for $900 \mathrm{~K}$ condition to get the averaged lift-off length reported in Fig. 17. The influence of different realizations on ignition delay and lift-off length is discussed further later in the paper.

\subsection{Soot predictions}

Previous sections have highlighted that LES can better predict ignition and combustion characteristics compared to RANS except for the lift-off length at higher ambient temperature conditions. Further examination on soot predictions is presented in this section. Soot modeling has been a challenging task and has drawn a lot of attention due to the importance of emission predictions at engine conditions. Some effort has been focused on developing different levels of details of soot models [52-54]. In this section, an empirical Hiroyasu soot model with $\mathrm{C}_{2} \mathrm{H}_{2}$ as a soot precursor is used to assess its validity in the context of high-fidelity LES simulations.

Figure 18 shows a comparison of soot contours from experiments (lineof-sight), LES, and RANS at different timings for the $900 \mathrm{~K}$ ambient temperature condition. The experimental and simulation contours are for a single shot and are not ensemble-averaged. It can be clearly observed from Fig. 18(c) that the locations predicted by RANS are quite different compared to experiments. RANS locates the soot clouds further upstream compared to the experiments. On the other hand, LES calculations (in Fig. 18(b)) are in very good agreement with experiments not only on the location, but also 


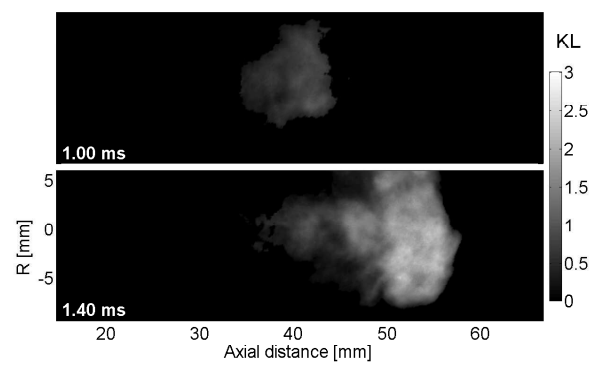

(a) Experiment

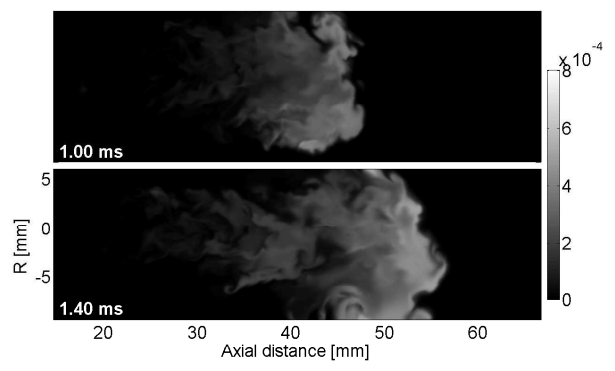

(b) LES

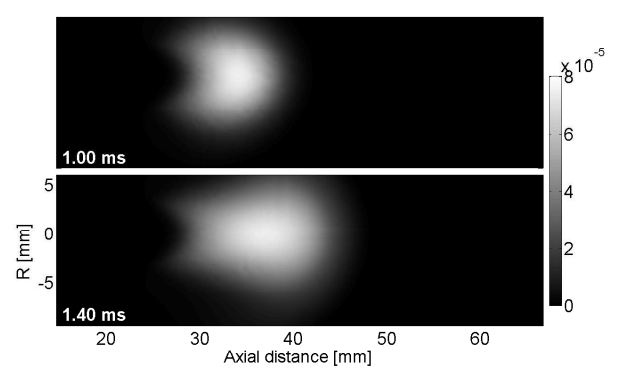

(c) RANS

Figure 18: Soot comparison from (a) Experiment (KL factor), (b) LES (mass fraction) and (c) RANS (mass fraction) at 1 and $1.4 \mathrm{~ms}$ for $900 \mathrm{~K}$ ambient temperature condition.

on the shape of the soot clouds, although they are broader than those from the experiments.

Figure 19 presents the comparison of total soot mass in the domain from experiments, LES, and RANS for the $900 \mathrm{~K}$ ambient temperature condition. RANS clearly underpredicts the total soot mass in the domain while LES is in excellent agreement with experiments, although the onset time of soot is slightly smaller than experiments. However, this comparison cannot be over interpreted because the soot model used here is an empirical model and one can simply adjust some constants to match the measurements even for 


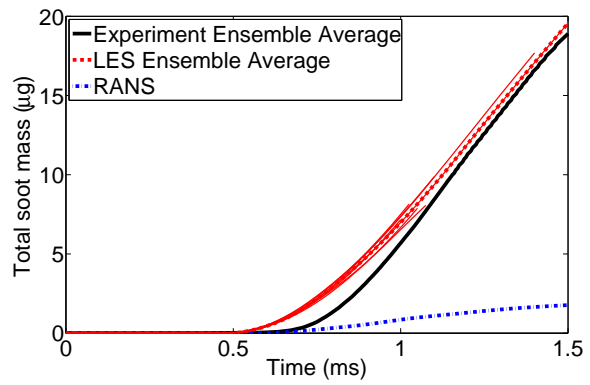

Figure 19: Comparison of the total soot mass in the domain between experiments, LES, and RANS at $900 \mathrm{~K}$ ambient temperature condition. The red dashed line is the ensemble-averaged total soot mass over different LES realizations and the solid red lines are the single LES realizations.

the RANS simulation. Another interesting observation is that the total soot mass in the domain does not vary much for different LES realizations. This is expected since a previous study has shown that the global indicators such as liquid length and vapor penetration length are less sensitive to realization variations [16].

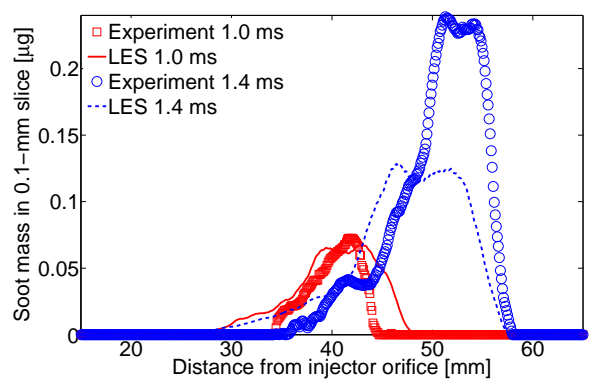

Figure 20: Comparison of the soot mass in $0.1 \mathrm{~mm}$ slice in the domain between LES and experiments at 1.0 and $1.4 \mathrm{~ms}$ for the $900 \mathrm{~K}$ ambient temperature condition.

Nevertheless, based on the current setup of the soot model, further examinations are made in Figs. 20 and 21 where the soot mass in different axial 
locations ( $0.1 \mathrm{~mm}$ slice) are depicted to show the onset locations at different timings. Figure 20 reports the comparison of soot onset locations between LES and experiments at 1.0 and $1.4 \mathrm{~ms}$. It can be seen that the onset locations for experiments are almost the same, and at $35 \mathrm{~mm}$ for 1.0 and 1.4 ms time instants. The onset locations for LES are also identical at 1.0 and $1.4 \mathrm{~ms}$, but located further upstream around $29 \mathrm{~mm}$. At $1.0 \mathrm{~ms}$, the leading soot front in the axial direction is further downstream for LES compared to the measurements, but the axial locations of the soot peak are the same. While at $1.4 \mathrm{~ms}$, the leading soot front from LES is in good agreement with the experiments, but the location of soot peak shifts about $5 \mathrm{~mm}$ upstream for LES. The soot onset locations for different LES realizations at $1.0 \mathrm{~ms}$ are reported in Fig. 21. As one can see the variation becomes larger with different LES realizations due to the localness of the parameter studied. The black solid line is the ensemble-averaged soot mass in $0.1 \mathrm{~mm}$ slice which also shows a further upstream soot onset location and similar soot peak location compared to the measurements.

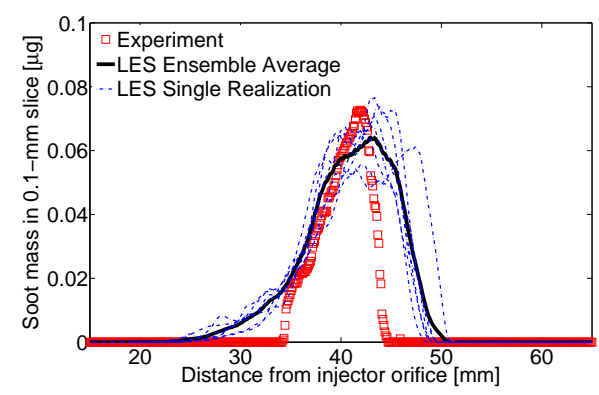

Figure 21: Comparison of the soot mass in $0.1 \mathrm{~mm}$ slice in the domain at $0.1 \mathrm{~ms}$ between different LES realizations, the ensemble-averaged values and the experiments at the 900 $\mathrm{K}$ ambient temperature condition. 


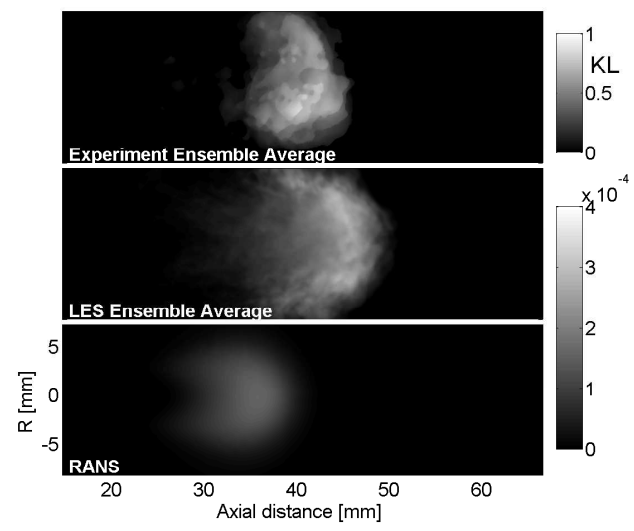

Figure 22: Comparison of the ensemble-averaged soot on the cross section along the spray axis for LES, experiments and RANS at $1 \mathrm{~ms}, 900 \mathrm{~K}$ ambient temperature condition. The color bar for experiments are KL factors and for simulations are the mass fraction.

Figure 22 shows the comparison of the ensemble-averaged soot on the cross section along the spray axis for LES, experiments, and RANS at $1.0 \mathrm{~ms}$ for the $900 \mathrm{~K}$ ambient temperature conditions. Similar to the observations in Figs. 20 and 21, LES exhibits a slightly longer and broader soot cloud, but a similar cloud shape. The soot cloud for RANS is much narrower and further upstream.

Overall, considering the fact that the Hiroyasu soot model is elementary, its performance is encouraging when coupled with high-fidelity LES simulations. Future work can focus on more detailed soot models within the context of LES.

\subsection{Relevance index}

After presenting detailed qualitative and quantitative flame structure comparisons between LES, RANS, and experiments, as well as demonstrating that the LES model can provide promising predictions, this section focuses 
on how to utilize these predictions from LES and how many realizations are needed to obtain reasonable ensemble results. Recall that Fig. 10 shows the cross section contours of mixture fraction, temperature, $\mathrm{OH}$, and soot mass fraction along the spray axis for different realizations and also the ensembleaveraged contours for 16 realizations at $900 \mathrm{~K}$ ambient condition. The flame structures shown in Fig. 10 are very different for different realizations. Each realization is perturbed by using different random number seeds for the sprays following the authors' previous studies $[16,46]$. This small perturbation clearly results in injection-to-injection variation from the LES calculations. The ensemble-averaged plots are much smoother. Although not shown here, RANS calculations do not show any variations in flame structure from realization to realization due to these small perturbations. This is due to the RANS modeling philosophy wherein small perturbations in the flow-field are dissipated whereas in LES these perturbations further grow with time.

Figure 23 shows the temporal lift-off length for 16 different LES realizations and also the averaged value over these realizations. One may clearly notice the difference in lift-off length between different realizations is significant. Corresponding to Fig. 23, the ignition delays are presented in Table 2, where only 5 realizations are shown and around $5 \%$ of variability is found. This demonstrates that a single realization may not be representative of LES results as claimed in Fig. 17.

Since there are significant differences between different realizations for the LES model, the authors performed 16 realizations for the Spray A flame at the $900 \mathrm{~K}$ condition. The computational cost of each calculation was in the order of 3 weeks on 256 processors with a peak cell count of about 


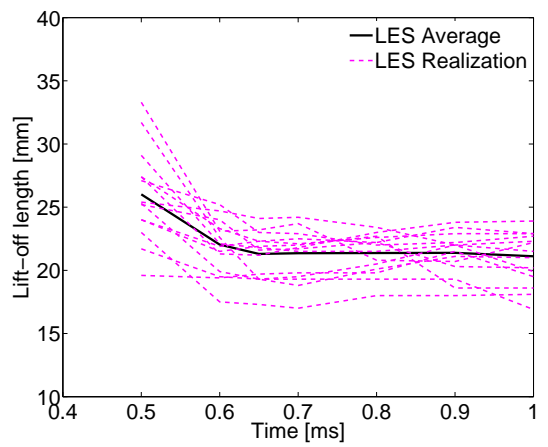

Figure 23: Temporal lift-off length for 5 different LES realizations and the average value of these realizations.

Table 2: Ignition delay for 5 different

LES realizations and the averaged value of different realizations.

\begin{tabular}{ll} 
Realization & Ignition delay $(\mathrm{ms})$ \\
1 & 0.5 \\
2 & 0.475 \\
3 & 0.475 \\
4 & 0.475 \\
5 & 0.45 \\
Average & 0.475 \\
\hline
\end{tabular}


22 million at $1 \mathrm{~ms}$. The computational cost of a RANS calculation is 12 hours on 16 processors with a peak cell count of about $144 \mathrm{~K}$ at $1 \mathrm{~ms}$. The parallelization efficiency of the code has been investigated by Kodavasal et al. [55] on a gasoline compression ignition engine simulation, where $75 \%$ of scaling efficiency can be achieved on 4096 processors.

It is clear that each realization is significantly more expensive with LES and the need for multiple realizations makes LES calculations indeed very expensive for regular use in the engine modeling community. In order to quantify the injection-to-injection variation and estimate the number of LES realizations required to compare with experiments, relevance index (RI) is defined as:

$$
f_{m, n}=\frac{(m, n)}{\|m\|\|n\|}
$$

where $m$ and $n$ are two vectors (e.g., mixture fraction or temperature as shown in Fig. 10), and represent the average over a different number of realizations (as indicated by the x-axis of Fig. 24) and the average over 16 realizations (the target), respectively. $(m, n)$ represents an inner product and, $\|m\|$ and $\|n\|$ are the magnitudes of the vectors. The vectors of interest were interpolated onto a uniform grid to perform the index calculations. Previous study [16] suggested that 10 realizations were required for non-reacting spray to extract useful information for comparison with experiments. Here, 16 realizations were performed and used as a target $n$.

The relevance index of different scalars for different numbers of realizations is plotted at $1.0 \mathrm{~ms}$ in Fig. 24. The relevance index increases with the number of realizations which is expected. For example, the relevance index of the mixture fraction in Fig. 24 initially increases rapidly with 2 to 


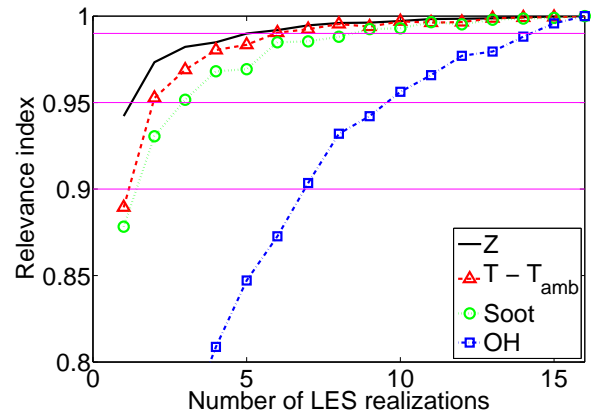

Figure 24: Relevance index of different scalars for different numbers of realizations at 1 ms for the $900 \mathrm{~K}$ ambient temperature condition.

3 realizations and then becomes rather flat with more than 5 realizations. Averaging over 5 realizations produces a relevance index of about $99 \%$ for mixture fraction, given the target is the average of 16 realizations. However, this scenario may be different for different scalars of interest. It is found that 6 realizations would be enough to reach $99 \%$ of similarity for temperature ${ }^{1}$, while 8 and 14 realizations are required to achieve $99 \%$ similarity for soot and $\mathrm{OH}$ mass fraction, respectively. More realizations are necessary for $\mathrm{OH}$ and soot due to more fluctuations and less similarity between each realization. The relevance index of different scalars at $0.8 \mathrm{~ms}$ were also examined and are very similar to the ones at $1 \mathrm{~ms}$, and therefore is not shown here. The analysis of relevance index here will provide a guide on performing LES simulations of spray flames at engine conditions.

\footnotetext{
${ }^{1}$ The ambient temperature is subtracted from the temperature field to be consistent with other scalars that have zero ambient values.
} 


\section{Summary and conclusions}

A reacting spray flame, Spray A, was modeled using a $\delta$ function combustion model (for n-dodecane fuel) in conjunction with a dynamic structure LES model on a high-resolution mesh across a wide range of ambient temperature conditions. Different mesh resolutions were examined by comparing different scalars, such as mixture fraction, temperature, $\mathrm{OH}$, and soot mass fraction on the cross section along the spray axis. The flame structure and ignition processes for LES are studied in detail and also compared to those from a RANS-based model. The variation with multiple realizations at 900 $\mathrm{K}$ ambient temperature condition was also examined. Soot predictions were also studied and compared with new experimental data. The relevance index criterion is defined to provide further guidance on the number of LES realizations needed to compare with the measurements.

The following findings were inferred from the LES model results:

- A mesh resolution with minimum cell size of $0.0625 \mathrm{~mm}$ is found to be close to provide mesh convergent predictions. Ignition delay predictions are not sensitive to the mesh resolution since it is mainly driven by the chemical kinetics.

- The LES results suggest that the first ignition initiates in a lean mixture, propagates to a rich mixture, and promotes the ignition there. In space, the first ignition occurs outside of the stoichiometric mixture fraction contour.

- The LES results also show that the main ignition happens in the rich mixture, preferably less than 0.14 in mixture fraction. Very different 
patterns of the scatter plot were found during the main ignition. LES also shows multiple ignition spots in the mixing layer compared to only one location shown in the RANS predictions.

- Significantly different flame structures are found between LES and RANS predictions on different scalar fields, such as mixture fraction, temperature, $\mathrm{OH}$, and soot mass fraction, etc.

- Overall, quantitative predictions of LES for ignition delay and lift-off length are better than those of RANS when compared with experiments.

- Soot predictions by LES present much better agreement with experiments compared to RANS both qualitatively and quantitatively.

- The relevance index analysis suggests at least 5 realizations are needed to obtain $99 \%$ similarity for mixture fraction if an average of 16 realizations are used as the target. However, this scenario may be different for different scalars of interest. It is found that 6 realizations would be enough to reach $99 \%$ of similarity for temperature, while 8 and 14 realizations are required to achieve $99 \%$ similarity for soot and $\mathrm{OH}$ mass fraction, respectively.

Overall, the LES calculations, although significantly more expensive than RANS, were shown to better mimic experimental data for all the parameters considered. Due to the advent of high performance computing resources [56], such LES calculations are becoming more tractable for internal combustion engine simulations. 


\section{Acknowledgments}

The submitted manuscript has been created by UChicago Argonne, LLC, Operator of Argonne National Laboratory (Argonne). Argonne, a U.S. Department of Energy Office of Science laboratory, is operated under Contract No. DE-AC02-06CH11357. The U.S. Government retains for itself, and others acting on its behalf, a paid-up nonexclusive, irrevocable worldwide license in said article to reproduce, prepare derivative works, distribute copies to the public, and perform publicly and display publicly, by or on behalf of the Government.

This research was funded by U.S. DOE Office of Vehicle Technologies, Office of Energy Efficiency and Renewable Energy under Contract No. DEAC02-06CH11357. The authors wish to thank Gurpreet Singh and Leo Breton, program managers at U.S. DOE, for their support.

We gratefully acknowledge the computing resources provided on Fusion, a computing cluster operated by the Laboratory Computing Resource Center at Argonne National Laboratory. The authors would also thank Prof. Evatt R. Hawkes at The University of New South Wales, Prof. Tianfeng Lu at University of Connecticut, Dr. Jacqueline H. Chen at Sandia National Laboratory, Dr. Muhsin Ameen at Argonne National Laboratory, Dr. Bing $\mathrm{Hu}$ at Cummins Engine Company, Mr. Mingjie Wang at Convergent Science Inc., and Mr. Prithwish Kundu at North Carolina State University for many helpful discussions.

\section{References}

[1] U. S. DOE, PreSICE, Workshop, U.S. Department of Energy (2011). 
[2] J. E. Dec, Proc. Combust. Inst. 32 (2009) 2727-2742.

[3] M. P. Musculus, P. C. Miles, L. M. Pickett, Prog. Energy Combust. Sci. 39 (2013) 246-283.

[4] S. B. Pope, Turbulent flows, Cambridge University Press, 2000.

[5] S. B. Pope, New Journal of Physics 6 (2004) 35.

[6] C. Rutland, International Journal of Engine Research (2011) 421-451.

[7] C. Bekdemir, L. Somers, L. de Goey, J. Tillou, C. Angelberger, Proc. Combust. Inst. 34 (2013) 3067-3074.

[8] J. Tillou, J.-B. Michel, C. Angelberger, D. Veynante, Combust. Flame 161 (2014) 525-540.

[9] M. M. Ameen, J. Abraham, SAE paper, 2014-01-1118 (2014).

[10] A. Irannejad, A. Banaeizadeh, F. Jaberi, Combust. Flame 162 (2015) 431-450.

[11] C. Gong, M. Jangi, X.-S. Bai, Applied Energy 136 (2014) 373-381.

[12] L. Pickett, G. Bruneaux, R. Payri, Engine Combustion Network, http://www.ca.sandia.gov/ecn (2014).

[13] S. Som, D. E. Longman, Z. Luo, M. Plomer, T. Lu, P. K. Senecal, E. Pomraning, J. Energy Resour. Technol. 134 (2012) 032204.

[14] Y. Pei, E. R. Hawkes, S. Kook, Proc. Combust. Inst. 34 (2013) 3039 3047. 
[15] Y. Pei, E. R. Hawkes, S. Kook, Flow, Turbul. Combust. 91 (2013) 249280.

[16] Q. Xue, S. Som, P. K. Senecal, E. Pomraning, Atomization Sprays 23 (2013) 925-955.

[17] G. D’Errico, T. Lucchini, F. Contino, M. Jangi, X.-S. Bai, Combust. Theor. Model. 18 (2013) 65-88.

[18] S. Bhattacharjee, D. C. Haworth, Combust. Flame 160 (2013) 20832102 .

[19] P. Kundu, Y. Pei, M. Wang, M. Raju, S. Som, Atomization Sprays 24 (2014) 779-800.

[20] M. Chishty, Y. Pei, E. Hawkes, M. Bolla, S. Kook, $19^{\text {th }}$ Australasian Fluid Mechanics Conference, Melbourne, Australia, 8-11 December (2014).

[21] M. Bolla, D. Farrace, Y. M. Wright, K. Boulouchos, E. Mastorakos, Combust. Theor. Model. 18 (2014) 330-360.

[22] Y. Pei, E. R. Hawkes, S. Kook, G. M. Goldin, T. Lu, Combust. Flame 162 (2015) 2006-2019.

[23] Y. Pei, M. J. Davis, L. M. Pickett, S. Som, Combust. Flame 162 (2015) $2337-2347$.

[24] Y. Pei, E. R. Hawkes, M. Bolla, M. Chishty, S. Kook, G. M. Goldin, Y. Yang, S. B. Pope, S. Som, Combust. Flame, submitted (2015). 
[25] Y. Pei, M. Mehl, W. Liu, T. Lu, W. J. Pitz, S. Som, J. Eng. Gas Turb. Pwr. 137 (2015) 11502.

[26] A. Kösters, A. Karlsson, M. Oevermann, G. D'Errico, T. Lucchini, Combust. Theor. Model. (2015) 81-106.

[27] R. Payri, J. P. Viera, Y. Pei, S. Som, Fuel 158 (2014) 957-967.

[28] L. M. Pickett, C. L. Genzale, G. Bruneaux, L.-M. Malbec, L. Hermant, C. Christiansen, J. Schramm, SAE Int. J. Engines 3 (2010) 156-181.

[29] L. M. Pickett, J. Manin, C. L. Genzale, D. L. Siebers, M. P. Musculus, C. A. Idicheria, SAE Int. J. Engines 4 (2011) 764-799.

[30] S. A. Skeen, J. Manin, L. M. Pickett, Proc. Combust. Inst. 35 (2015) $3167-3174$.

[31] J. Manin, L. M. Pickett, S. A. Skeen, SAE Int. J. Engines 6 (2013) 1908-1921.

[32] S. Som, S. Aggarwal, Combust. Flame 157 (2010) 1179-1193.

[33] P. Senecal, K. Richards, E. Pomraning, T. Yang, M. Dai, R. McDavid, M. Patterson, S. Hou, T. Shethaji, SAE paper, 2007-01-0159 (2007).

[34] K. Richards, P. Senecal, E. Pomraning, CONVERGE (Version 2.1) Manual, Technical Report, Convergent Science, Inc., Madison, WI, 2013.

[35] S. Som, Development and validation of spray models for investigating diesel engine combustion and emissions, Ph.D. thesis, University of Illinois at Chicago, 2009. 
[36] R. D. Reitz, Atomisation Spray Technol. 3 (1987) 309-337.

[37] M. A. Patterson, R. D. Reitz, SAE paper, 980131 (1998).

[38] D. P. Schmidt, C. Rutland, J. Comput. Phys. 164 (2000) 62-80.

[39] N. Frossling, N.A.C.A. 168 (1956) AD-B189.

[40] A. B. Liu, D. Mather, R. D. Reitz, SAE paper, 930072 (1993).

[41] P. Senecal, E. Pomraning, K. Richards, T. Briggs, C. Choi, R. McDavid, M. Patterson, SAE paper, 2003-01-1043 (2003).

[42] Z. Luo, S. Som, S. M. Sarathy, M. Plomer, W. J. Pitz, D. E. Longman, T. Lu, Combust. Theor. Model. 18 (2014) 187-203.

[43] J. Kodavasal, S. Keum, A. Babajimopoulos, Combust. Theor. Model. 15 (2011) 893-910.

[44] H. Hiroyasu, T. Kadota, SAE paper, 760129 (1976).

[45] E. Pomraning, C. J. Rutland, AIAA journal 40 (2002) 689-701.

[46] P. Senecal, E. Pomraning, K. Richards, S. Som, SAE paper, 2013-011083 (2013).

[47] P. Senecal, S. Mitra, E. Pomraning, Q. Xue, S. Som, S. Banerjee, B. Hu, K. Liu, D. Rajamohan, J. Deur, J. Eng. Gas Turb. Pwr. 136 (2015) 111504 .

[48] S. Skeen, J. Manin, L. M. Pickett, SAE Int. J. Engines 8 (2015) 696-715. 
[49] E. Hawkes, Y. Pei, S. Kook, S. Sibendu, Proc. Australian Combust. Symp., Perth, Australia, 6-8 November (2013).

[50] Y. Pei, Transported PDF Modelling of Spray Combustion at Practical Diesel Engine Conditions, Ph.D. thesis, The University of New South Wales, Sydney, Australia, 2013.

[51] P. M. Lillo, L. M. Pickett, H. Persson, O. Andersson, S. Kook, SAE Int. J. Engines 5 (2012) 1330-1346.

[52] M. Bolla, Y. M. Wright, K. Boulouchos, G. Borghesi, E. Mastorakos, Combust. Sci. Technol. 185 (2013) 766-793.

[53] V. R. Mohan, D. Haworth, Proc. Combust. Inst. 35 (2015) 3053-3060.

[54] F. Tao, R. D. Reitz, D. E. Foster, Y. Liu, Int. J. Therm. Sci. 48 (2009) 1223-1234.

[55] J. Kodavasal, K. Harms, P. Srivastava, S. Som, S. Quan, K. Richard, M. Garcia, ASME ICEF 2015-1035 (2015).

[56] S. Som, D. Longman, S. Aithal, R. Bair, M. García, S. Quan, K. Richards, P. Senecal, T. Shethaji, M. Weber, SAE paper (2013) 2013-01-1095. 